\title{
Increasing omega fatty acid content in cow's milk through diet manipulation: Effect on milk flavor
}

\author{
K. A. S. Nelson* and S. Martini ${ }^{1}$ \\ *Department of Animal, Dairy and Veterinary Sciences, Utah State University, Logan 84322-4815 \\ †Department of Nutrition and Food Sciences, Utah State University, Logan 84322-8700
}

\begin{abstract}
Milk with an increased content of eicosapentaenoic acid (EPA), docosahexaenoic acid (DHA), and conjugated linoleic acid (CLA) was obtained by incorporating fish oil into the feed of cows. The 4 feed treatments used were a control diet of $57 \%$ forage and $43 \%$ concentrate mix with EnerGII fat supplement at $1.65 \%$ of dietary DM, or EnerGII in the basal diet was partially replaced with 1) $0.21 \%$ partially ruminally inert calcium salts of $71 \%$ fish oil given at $0.41 \%$ of DM; 2) $0.41 \%$ inert calcium salts of $71 \%$ fish oil given at $0.83 \%$ of $\mathrm{DM}$; or 3) $0.83 \%$ inert calcium salts of $43 \%$ fish oil given at $0.83 \%$ of DM. The cows were milked after 5 and 8 wk and the EPA, DHA, and CLA contents in the pasteurized whole milk were determined. The presence of off-flavors in the milk was investigated after 3 and 10 $\mathrm{d}$ of storage. Twelve judges were trained to evaluate the presence of grassy, fishy, oily, oxidized, and rancid offflavors. Although levels of EPA, DHA, vaccenic acid, and CLA increased for all 4 treatments, a trained sensory panel detected no difference in milk flavor between treatments and the control, with little or no intensity of off-flavors. Results suggest that feeding fish oil and EnerGII at varying levels enhanced CLA, EPA, DHA, and total n-3 fatty acids in milk over the length of the experiment without negatively affecting milk flavor. This creates the potential for a more marketable and healthful product.
\end{abstract}

Key words: sensory evaluation, milk, fish oil, flavor

\section{INTRODUCTION}

It has been demonstrated that n-3 fatty acids (FA), specifically eicosapentaenoic acid (EPA) and docosahexaenoic acid (DHA), can significantly decrease the risks of cardiovascular disease, hypertension, certain autoimmune and inflammatory diseases, behavior problems, and cancer (Simopoulos, 1991; Ruxton,

Received October 6, 2008.

Accepted December 8, 2008.

${ }^{1}$ Corresponding author: silvana.martini@usu.edu
2004). These FA are also essential to the development of the brain and retina, and to normal cell function and growth (Simopoulos, 1991). The possible health benefits of conjugated linoleic acid (CLA) are anticarcinogenicity, antiatherogenicity, growth promotion, antiobesity, and immunomodulation, with the anticarcinogenic properties being among the most desirable and pertinent (Chouinard et al., 1999; Baer et al., 2001; Hughes and Dhiman, 2002).

Although the aforementioned FA carry the potential to be beneficial to humans, the difficulty lies in determining the vehicle that will provide all these FA. Dairy products, along with ruminant meat, are the greatest sources of CLA in human diets (Hughes and Dhiman, 2002; Dhiman et al., 2005). Simple diet manipulation in cows can increase CLA, and subsequently the benefits of dairy products (Chouinard et al., 2001). Although fish oil (FO) has been recognized as the best supplemental source for n-3 FA, it is not conducive to fortification with respect to sensory evaluations, especially when added to dairy products with low fat content, such as milk (Simopoulos, 1991; Kolanowski and Wießbrodt, 2007). Fortification of dairy products with FO can result in a host of problems, including the following: it is difficult to reach levels high enough to be effective without causing fishy or other off-flavors; high susceptibility to oxidation of FO can cause further formation of off-flavors; and masking of off-flavors with desirable flavoring (e.g., strawberry or garlic) creates potential health risks (Kolanowski and Wießbrodt, 2007). Because fortification of dairy products with FO appears to be an undesirable mode of consuming combined beneficial doses of n-3 FA and CLA, eating dairy products from animals fed a diet including FO and linoleic acid-rich feed seems to be the best alternative. This provides the consumer with a more healthful and acceptable product while aiding in meeting the suggested beneficial levels of intake for n-3 FA and CLA, without significantly altering the diet of the consumer. To ensure complete safety for the consumer, more studies should be performed with this type of milk to verify safe consumption on a daily basis. The objective of this experiment was to enhance the CLA and n-3 FA content of milk through diet manipulation 
while maintaining the flavor quality of the milk over the length of the experiment.

\section{MATERIALS AND METHODS}

\section{Diet Treatments}

Twenty multiparous Holstein cows averaging $156 \pm$ 45 DIM were selected from the general herd at the Caine Dairy of Utah State University. Cows were blocked into 5 different groups according to average milk yield 10 $\mathrm{d}$ before the beginning of the experiment. Cows had an average BW of $750.5 \pm 58.6 \mathrm{~kg}$ at the beginning of the experiment. Cows within each group were randomly assigned to 1 of 4 treatments. Experimental duration was 9 wk, which included a 3 -wk diet adaptation at the beginning of the experiment. The experiment ran from late May until the end of July 2007. Cows were fed a nonexperimental TMR in a tie-stall barn 1 wk before the beginning of the experiment for adjustment to the barn. Measurements were made during the last $6 \mathrm{wk}$ of the experiment. Cows in the 4 treatments were fed either a control diet of $57 \%$ forage and $43 \%$ concentrate mix with EnerGII fat supplement at $1.65 \%$ of dietary DM (CTL), or EnerGII in the basal diet was partially replaced with 1) $0.21 \%$ partially ruminally inert calcium salts of $71 \%$ FO given at $0.41 \%$ of DM (FH41); 2) $0.41 \%$ inert calcium salts of $71 \% \mathrm{FO}$ given at $0.83 \%$ of DM (FH83); or 3) $0.83 \%$ inert calcium salts of $43 \%$ FO given at $0.83 \%$ of DM (FL). Virtus Nutrition Inc. (Corcoran, CA) supplied all FA supplements. Diets were formulated to meet the nutrient requirements of cows producing $48 \mathrm{~kg}$ of $3.5 \% \mathrm{FCM} / \mathrm{d}$ according to NRC (2001) recommendations and fed as TMR. Diets were similar except for fat supplementation, which never exceeded or went below $1.65 \%$ of DM and differed only in the type and combination of supplementationEnerGII, $71 \%$ FO, or $43 \%$ FO. The diet composition for each treatment is given in Table 1. Fresh water was available at all times. Cows were fed twice daily (0430 and $1530 \mathrm{~h}$ ) ad libitum, with the amount fed and orts recorded daily. Orts were targeted to 5 to $10 \%$ of daily intake (as fed). Supplements were weighed according to each treatment for each feeding, added to the TMR, and then promptly fed. Animal care and procedures were approved and conducted under established standards of the Utah State University Institutional Animal Care and Use Committee.

\section{Milk Collection and Processing}

Milk collection was done daily on an individual cow basis. Weekly milk samples were collected from each cow from 4 consecutive a.m. and p.m. milkings (0445 and $1645 \mathrm{~h}$ ) at the end of each week during wk 4 through
9. A Broad Spectrum Microtabs II (D \& F Control Systems Inc., San Ramon, CA) preservative was added to each sample in tablet or liquid form and samples were stored at $4^{\circ} \mathrm{C}$ until analyzed for FA content. (Additional analyses of production variables such as milk protein, fat, and so on are currently unpublished data.) Analysis was conducted within 1 wk of collection. Leftover milk for laboratory analysis was stored at $-20^{\circ} \mathrm{C}$ for future reference.

During wk 5 and 8, milk from 2 consecutive milkings for each cow was collected in vacuum-sealed milking cans. Milk was collected during these weeks to evaluate the effect and possible differences created by time. The milk was transferred into plastic $20-\mathrm{L}$ buckets, labeled by treatment and cow, and transported within $45 \mathrm{~min}$ of cessation of milk collection from the dairy to the Gary H. Richardson Dairy Products Laboratory at Utah State University. On arrival at the Dairy Products Laboratory, the milk was cooled to $4^{\circ} \mathrm{C}$ within $2 \mathrm{~h}$ after collection. Approximately $8 \mathrm{~kg}$ of milk/cow per milking was combined for each treatment, with a total of $80 \mathrm{~kg}$ of milk/treatment for each week. Samples were heated to $65.5^{\circ} \mathrm{C}$ and homogenized using a Gaulin model CGC 2-stage homogenizer (Gaulin, Everette, MA) at 13.8 $\mathrm{MPa}$ and $35 \mathrm{MPa}$, and then pasteurized at $73^{\circ} \mathrm{C}$ for 16 s using an APV Model SR15-S pasteurizer (APV Equipment Inc., Tonawanda, NY). After pasteurization, samples were cooled from 164 to $45^{\circ} \mathrm{F}$ in $1 \mathrm{~min}$. Approximately $19 \mathrm{~kg}$ of homogenized and pasteurized milk for each treatment was stored in 37.8-L stainless steel milking cans at $3.9^{\circ} \mathrm{C}$. Sensory evaluation of milk was conducted within $72 \mathrm{~h}$ of procurement and within $36 \mathrm{~h}$ of processing the milk without standardizing for fat content. An additional sensory evaluation of the same milk for each indicated week was conducted 7 $\mathrm{d}$ after the initial $72 \mathrm{~h}\left(10 \mathrm{~d}\right.$ of storage at $\left.3.9^{\circ} \mathrm{C}\right)$ to simulate aging of milk in the refrigerators of consumers and the effect of storage time on flavor.

\section{Determination of Milk FA Composition}

Weekly weighted composite milk samples from individual cows were analyzed for FA composition, including CLA, vaccenic acid, and n-3 FA. Milk fat was extracted by boiling the milk in a detergent solution (Hurley et al., 1987). Extracted fat was derivatized to methyl esters using an alkaline methylation procedure by mixing $40 \mathrm{mg}$ of fat with sodium methoxide methylation reagent $\left(\mathrm{NaOCH}_{3} / \mathrm{MeOH}\right)$ as described by Chouinard et al. (1999), with minor modifications. After FA methyl esters were formed, anhydrous calcium chloride pellets were added and the samples were allowed to stand for $1 \mathrm{~h}$ to remove water. Samples were then centrifuged at $2,600 \times g$ at $5^{\circ} \mathrm{C}$ for $5 \mathrm{~min}$. 
Table 1. Ingredient and chemical composition of diets

\begin{tabular}{|c|c|c|c|c|}
\hline \multirow[b]{2}{*}{ Item } & \multicolumn{4}{|c|}{ Treatment, ${ }^{1} \mathrm{~g} / 100 \mathrm{~g}$ of DM } \\
\hline & CTL & FH41 & FH83 & $\mathrm{FL}$ \\
\hline \multicolumn{5}{|l|}{ Ingredient } \\
\hline Alfalfa hay & 25.72 & 25.72 & 25.72 & 25.72 \\
\hline Corn silage & 31.08 & 31.08 & 31.08 & 31.08 \\
\hline Steam-rolled corn & 13.38 & 13.38 & 13.38 & 13.38 \\
\hline Almond hulls & 1.60 & 1.60 & 1.60 & 1.60 \\
\hline Corn dried distillers grain & 1.83 & 1.83 & 1.83 & 1.83 \\
\hline Corn, hominy & 3.65 & 3.65 & 3.65 & 3.65 \\
\hline Canola meal, mechanically extracted & 1.37 & 1.37 & 1.37 & 1.37 \\
\hline Whole-linted cottonseed & 5.28 & 5.28 & 5.28 & 5.28 \\
\hline Soybean meal, expeller & 1.10 & 1.10 & 1.10 & 1.10 \\
\hline Blood meal, ring dried & 0.73 & 0.73 & 0.73 & 0.73 \\
\hline Calcium salts of palm oil (EnerGII) & 1.65 & 1.24 & 0.82 & 0.82 \\
\hline Calcium salts of fish oil, $71 \%$ & 0.00 & 0.41 & 0.83 & 0.00 \\
\hline Calcium salts of fish oil, $43 \%$ & 0.00 & 0.00 & 0.00 & 0.83 \\
\hline Molasses, sugar beet & 2.14 & 2.14 & 2.14 & 2.14 \\
\hline Minerals and vitamin mix & 1.39 & 1.39 & 1.39 & 1.39 \\
\hline \multicolumn{5}{|l|}{ Chemical, g/100 g of DM } \\
\hline $\mathrm{NE}_{\mathrm{L}}, \mathrm{Mcal} / \mathrm{kg}$ of $\mathrm{DM}$ & 1.30 & 1.30 & 1.30 & 1.30 \\
\hline $\mathrm{CP}$ & 17.70 & 17.70 & 17.70 & 17.70 \\
\hline Total fatty acids & 5.31 & 5.31 & 5.31 & 5.31 \\
\hline Eicosapentaenoic acid & 0.00 & 0.04 & 0.08 & 0.04 \\
\hline Docosahexaenoic acid & 0.00 & 0.03 & 0.07 & 0.04 \\
\hline Conjugated linoleic acid & 0.15 & 0.14 & 0.13 & 0.11 \\
\hline $\mathrm{NDF}$ & 29.60 & 29.60 & 29.60 & 29.60 \\
\hline $\mathrm{ADF}$ & 18.70 & 18.70 & 18.70 & 18.70 \\
\hline
\end{tabular}

${ }^{1}$ Cows in the 4 treatments were fed either a control diet of $57 \%$ forage and $43 \%$ concentrate mix with EnerGII fat supplement at $1.65 \%$ of dietary DM (CTL), or EnerGII in the basal diet was partially replaced with 1) $0.21 \%$ partially ruminally inert calcium salts of $71 \%$ fish oil (Ca-FO71) given at $0.41 \%$ of DM (FH41); 2 ) $0.41 \%$ inert Ca-FO71 given at $0.83 \%$ of DM (FH83); or 3) $0.83 \%$ inert calcium salts of $43 \%$ fish oil given at $0.83 \%$ of DM (FL). Virtus Nutrition Inc. (Corcoran, CA) supplied all FA supplements.

Separation of individual FA was achieved by using a gas chromatograph (Model QP2010, Shimadzu Co., Columbia, MD) fitted with a flame-ionization detector. Samples containing methyl esters in hexane $(1 \mu \mathrm{L})$ were injected onto an HP-88 fused-silica $100 \mathrm{~m} \times 0.25$ $\mathrm{mm}$ column, $0.20 \mu \mathrm{m}$ film (Agilent Technologies, Palo Alto, CA). The injection port was maintained at $250^{\circ} \mathrm{C}$ in the split mode, and the sample was split at a 100:1 ratio with a $3.0 \mathrm{~mL} / \mathrm{min}$ purge flow. Hydrogen was used as the carrier gas at a flow rate with a linear velocity of $41.1 \mathrm{~cm} / \mathrm{s}$. The temperature program was as follows: the initial temperature of $50^{\circ} \mathrm{C}$ was held for $1 \mathrm{~min}$, increased at $40^{\circ} \mathrm{C} / \mathrm{min}$ to $175^{\circ} \mathrm{C}$ and held for $4 \mathrm{~min}$, increased at $3.5^{\circ} \mathrm{C} / \mathrm{min}$ to $250^{\circ} \mathrm{C}$, and held for $3 \mathrm{~min}$. The detector was operated at $250^{\circ} \mathrm{C}$, and the makeup gas was nitrogen at $30 \mathrm{~mL} / \mathrm{min}$. Air flow to the detector was $450 \mathrm{~mL} / \mathrm{min}$ and hydrogen flow was $40 \mathrm{~mL} /$ min. Total run time was $32.55 \mathrm{~min} /$ sample.

Each peak was identified using FA and FA methyl esters (Nu-Chek Prep, Elysian, MN; Matreya, Pleasant Gap, PA; and Supelco 37-Component FA methyl ester mix, Supelco, Bellefonte, PA). Heptadecanoic acid was added as an internal standard. Percentage of each FA was calculated by dividing the area under the FA peak (minus the area under the peak for heptadecanoic acid) by the sum of the areas under the total reported FA peaks. Fatty acids are reported as grams per $100 \mathrm{~g}$ of FA methyl esters. The CLA yield was calculated by multiplying CLA content with total fat yield corrected for glycerol content (Chouinard et al., 2001) on an individual cow basis.

\section{Sensory Analysis}

A trained panel of 12 judges evaluated pasteurized and homogenized fluid milk samples from wk 5 and 8 for each treatment on 3 and $10 \mathrm{~d}$ of storage for grassy (feedy), fishy, oily, oxidized, and rancid off-flavors. Weeks acted as replicates for the treatments. Data were collected using an electronic data collection system (SIMS2000) and analyzed using SAS version 9.1.3 (SAS Institute, 1999-2000). Judges were trained for the proposed study, but many were already familiar with the scale for fluid milk flavor. Judges were trained for a total of $5 \mathrm{~h}$, and training procedures followed the guidelines described by Meilgaard et al. (2007). The training began 1 wk before sensory evaluation and continued once weekly until the last evaluation (10 d 
Table 2. Preparation of off-flavor reference samples

\begin{tabular}{|c|c|}
\hline Off-flavor & Preparation \\
\hline Grassy $^{2}$ & Add $20 \mathrm{mg}$ of hexanal to $1 \mathrm{~L}$ of milk. \\
\hline Oily $^{3}$ & Add 1 drop $(0.02 \mathrm{~g})$ of soybean oil to $50 \mathrm{~mL}$ of milk. \\
\hline Fishy $^{3}$ & Add 2,5 , or 7 drops of docosahexaenoic acid oil to $900 \mathrm{~mL}$ of milk. \\
\hline
\end{tabular}

${ }^{1}$ Adapted from Shipe et al. (1977).

${ }^{2}$ Adapted from Singh et al. (2003), Croissant et al. (2007), and Hongsoongnern and Chambers (2008).

${ }^{3}$ Developed by our group.

of refrigeration) for wk 8 samples. When a training session occurred on the same day as an evaluation, a 20-min break was given before testing. Training was performed at a round table, enabling interaction among the judges. The sensory evaluation was conducted using a categorized 5-point scale for flavor characteristics with the following categories: extremely strong, strong, moderate, slight, and no flavor. For statistical analysis, numerical scores were given to the categories, where $5=$ extremely strong flavor and $1=$ no flavor. Whole milk fortified with vitamin $\mathrm{D}$ in a clear plastic container was purchased from a store, with at least $14 \mathrm{~d}$ shelf life remaining, and was used as a control (STORE). Reference samples for specific attributes were provided for all flavor characteristics during training (Table 2).

During testing, refrigerated $\left(3.9 \pm 1.0^{\circ} \mathrm{C}\right)$ fluid milk from each treatment and STORE were served in unlidded, 59-mL plastic cups to the trained panel. Fifteen milliliters of the cold sample was poured into the cup just before tasting. Random code numbers were assigned to each sample for identification. Samples were also presented in a randomized and balanced way among judges. Sample tasting was performed in individual booths under fluorescent white light. Water and spittoons were provided to judges to cleanse the palate between samples.

\section{Statistical Analysis}

The design of the experiment was a split plot in which week was the whole plot, storage day was the subplot, and treatment (to include the STORE) was the block. Week provided the replication, with there being a total of 2 replications for each storage day and subsequent treatment. Treatment, week, storage day, judge, treatment $\times$ week, and storage day $\times$ week were included in the model. Statistical analyses were performed using the GLM procedure of SAS (SAS Institute, 1999-2000). Fixed effects were treatment, storage day, and judge. Significance level was declared at $P<0.05$, unless otherwise noted. Trends for significance were declared at $0.05 \leq P<1.0$. The covariance structure was diagonal.

\section{RESULTS AND DISCUSSION}

\section{FA Composition of Milk}

The FA composition of the milk (Table 3) showed that both CLA isomers were affected by treatment. Treatment FH83 had more of the trans-10, cis-12 isomer when compared with treatment FH41 (0.022 and $0.003 \mathrm{~g} / 100 \mathrm{~g}$, respectively). Treatment FH83 also had significantly greater levels $(P<0.001)$ of the cis-9, trans-11 isomer when compared with the other treatments (1.15 vs. $0.52,0.67$, and $0.80 \mathrm{~g} / 100 \mathrm{~g}$ for CTL, FH41, and FL, respectively), as well as total CLA. Treatments FH41, FH83, and FL displayed a 1.3-, 2.2-, and 1.5-fold increase of total CLA when compared with CTL. These higher levels of CLA can be partially attributed to the higher level of vaccenic acid, as found in FH83, and the activity of the $\Delta^{9}$-desaturase enzyme (Allred et al., 2006; Whitlock et al., 2006). Whitlock et al. (2006) noted that FO is needed to maximize CLA cis-9, trans-11 in milk, even if it is provided in small amounts. This is supported by the finding that all treatments fed FO in this experiment had greater concentrations of CLA in their milk than the CTL, despite the CTL initially having more CLA in the diet (Table 1).

Fatty acid analysis showed that both EPA and DHA contents in the milk were increased by treatment $(P=$ 0.014 for EPA and $P=0.003$ for DHA; Table 3$)$. As expected, EPA was significantly lower for CTL when compared with the other treatments because of the absence of FO. Because FO provides both EPA and DHA, it is not surprising that DHA followed the same pattern, with CTL having a significantly smaller amount than the other treatments. The DHA content in the milk was increased as much as 6 -fold when cows were fed FO, and EPA was increased by 2.7-fold when compared with the CTL. Interestingly, mean comparisons 
Table 3. Fatty acid composition of milk from cows fed varying amounts of calcium salts of fish oil (FO) and EnerGII

\begin{tabular}{|c|c|c|c|c|c|c|}
\hline \multirow[b]{2}{*}{ Fatty $\operatorname{acid}^{1}$} & \multicolumn{4}{|c|}{ Treatment, ${ }^{2} \mathrm{~g} / 100 \mathrm{~g}$ of fatty acids reported } & \multirow[b]{2}{*}{$P$-value ${ }^{3}$} & \multirow[b]{2}{*}{$\mathrm{SEM}^{4}$} \\
\hline & CTL & FH41 & FH83 & FL & & \\
\hline $\mathrm{C} 18: 1 t-11(\mathrm{VA})$ & $1.04^{\mathrm{a}}$ & $1.51^{\mathrm{a}}$ & $2.28^{\mathrm{b}}$ & $1.68^{\mathrm{ab}}$ & $* *$ & 0.18 \\
\hline C18:2 & $2.68^{\mathrm{a}}$ & $3.17^{\mathrm{b}}$ & $2.82^{\mathrm{ab}}$ & $3.08^{\mathrm{b}}$ & ** & 0.08 \\
\hline $\mathrm{C} 18: 3 \quad c-6,9,12$ & $0.04^{\mathrm{a}}$ & $0.02^{\mathrm{ac}}$ & $0.01^{\mathrm{b}}$ & $0.02^{\mathrm{bc}}$ & $* * *$ & 0.003 \\
\hline $\mathrm{C} 18: 3 c-9,12,15$ & 0.42 & 0.50 & 0.46 & 0.50 & 0.05 & 0.02 \\
\hline CLA $c-9, t-11$ & $0.52^{\mathrm{a}}$ & $0.67^{\text {ab }}$ & $1.15^{\mathrm{c}}$ & $0.80^{\mathrm{b}}$ & $* * *$ & 0.08 \\
\hline CLA $t-10, c-12$ & $0.02^{\mathrm{ab}}$ & $0.00^{\mathrm{a}}$ & $0.02^{\mathrm{b}}$ & $0.01^{\mathrm{ab}}$ & $*$ & 0.30 \\
\hline Total CLA & $0.54^{\mathrm{a}}$ & $0.68^{\mathrm{a}}$ & $1.18^{\mathrm{b}}$ & $0.82^{\mathrm{a}}$ & $* * *$ & 0.08 \\
\hline $\mathrm{C} 20: 3 c-8,11,14$ & $0.13^{\mathrm{ab}}$ & $0.11^{\mathrm{b}}$ & $0.06^{\mathrm{c}}$ & $0.09^{\mathrm{abc}}$ & $* *$ & 0.11 \\
\hline $\mathrm{C} 20: 3 c-11,14,17$ & $0.01^{\mathrm{a}}$ & $0.01^{\mathrm{ab}}$ & $0.04^{\mathrm{b}}$ & $0.02^{\mathrm{ab}}$ & $* * *$ & 0.12 \\
\hline C20:4 & $0.12^{\mathrm{a}}$ & $0.11^{\mathrm{ab}}$ & $0.08^{\mathrm{b}}$ & $0.09^{\mathrm{ab}}$ & ** & 0.006 \\
\hline $\mathrm{C} 20: 5$ (EPA) & $0.03^{\mathrm{a}}$ & $0.07^{\mathrm{b}}$ & $0.08^{\mathrm{b}}$ & $0.08^{\mathrm{b}}$ & $*$ & 0.01 \\
\hline $\mathrm{C} 22: 4$ & 0.02 & 0.02 & 0.02 & 0.02 & 0.09 & 0.001 \\
\hline C22:6 (DHA) & $0.02^{\mathrm{a}}$ & $0.09^{\mathrm{b}}$ & $0.12^{\mathrm{b}}$ & $0.11^{\mathrm{b}}$ & $* *$ & 0.02 \\
\hline Total $n-3^{5}$ & $0.52^{\mathrm{a}}$ & $0.76^{\mathrm{b}}$ & $0.82^{\mathrm{b}}$ & $0.80^{\mathrm{b}}$ & ** & 0.04 \\
\hline Total n- $6^{6}$ & $2.99^{\mathrm{a}}$ & $3.43^{\mathrm{b}}$ & $2.98^{\mathrm{a}}$ & $3.30^{\mathrm{ab}}$ & $*$ & 0.10 \\
\hline n-3:n-6 & $0.17^{\mathrm{a}}$ & $0.20^{\mathrm{b}}$ & $0.27^{\mathrm{c}}$ & $0.24^{\mathrm{bc}}$ & $* * *$ & 0.01 \\
\hline
\end{tabular}

\footnotetext{
${ }^{a-c}$ Means in the same row with different superscripts differ significantly for treatment effect, with $P$-value as mentioned in the column for significance.

${ }^{1}$ Expressed as number of carbons:number of double bonds; $c=$ cis, $t=$ trans. $\mathrm{VA}=$ vaccenic acid; $\mathrm{CLA}=$ conjugated linoleic acid; EPA = eicosapentaenoic acid; DHA = docosahexaenoic acid.

${ }^{2}$ Cows in the 4 treatments were fed either a control diet of $57 \%$ forage and $43 \%$ concentrate mix with EnerGII fat supplement at $1.65 \%$ of dietary DM (CTL), or EnerGII in the basal diet was partially replaced with 1) $0.21 \%$ partially ruminally inert calcium salts of $71 \%$ fish oil (Ca-FO71) given at $0.41 \%$ of DM (FH41); 2$) 0.41 \%$ inert Ca-FO71 given at $0.83 \%$ of DM (FH83); or 3) $0.83 \%$ inert calcium salts of $43 \%$ fish oil given at $0.83 \%$ of DM (FL). Virtus Nutrition Inc. (Corcoran, CA) supplied all FA supplements.

${ }^{3}$ Significance of effects of treatments.

${ }^{4} \mathrm{SEM}=$ standard error of the least squares means.

${ }^{5}$ Sum of C18:3 c-9,12,15; C20:3 c-11,14,17; C20:5 (EPA); and C22:6 (DHA).

${ }^{6} \mathrm{Sum}$ of $\mathrm{C} 18: 2 ; \mathrm{C} 18: 3 c-6,9,12 ; \mathrm{C} 20: 3 c-8,11,14 ; \mathrm{C} 20: 4 ;$ and $\mathrm{C} 22: 4$.

${ }^{*} P<0.05 ;{ }^{* *} P<0.01 ;{ }^{* * *} P<0.001$.
}

revealed that EPA and DHA levels did not differ $(P>$ 0.05 ) among the different concentrations (43 and $71 \%)$ and amounts of FO fed (FH41, FH83, and FL), despite the differing amounts of EPA and DHA in the diet (Table 1). These observations for EPA counter those found by Donovan et al. (2000) when feeding FO at 1, 2 or $3 \%$ of DM. They observed that EPA levels increased as the amount of FO increased. In agreement with our findings, however, Ramaswamy et al. (2001) found that varying levels of FO ( 1 and $2 \%$ of DM) and soybean meal produced similar levels of EPA.

\section{Sensory Evaluation of Milk}

Although we expected some off-flavors because of FA supplementation, especially of FO, the treatments that actually yielded those off-flavors, albeit slight, did not coincide with our initial predictions. Fish oil, in general, tends to yield a fishy off-flavor, especially when supplemented at high levels. Conjugated linoleic acid tends to yield a grassy off-flavor. It was also noted that oxidation of polyunsaturated FA could cause rancid and oxidative off-flavors, especially when unprotected, but the other off-flavors tested, in addition to oily, were not reported to be caused specifically by the diet. The higher contents of CLA, DHA, and EPA in the experimental milk raised the question of the flavor quality of the milk and the presence of off-flavors such as rancid, oxidized, fishy, oily, and grassy.

There was no difference $(P>0.05)$ between treatments, storage days, or their interaction for any of the off-flavors. Despite the lack of an overall effect of treatment, some trends are noteworthy and may have been statistically significant if EnerGII and FO supplements had been fed at higher levels; thus, these slight discrepancies are discussed. Although there were differences in the content of CLA between treatments, possible off-flavors (typically grassy) that can occur because of increased levels of CLA were not detected between treatments when the evaluation was conducted after $3 \mathrm{~d}$ of storage (Figure 1). Although not significant, there was a slight difference between STORE and the other treatments after $10 \mathrm{~d}$ of storage for grassy off-flavor (Figure 2 ). The slightly more intense grassy off-flavor in the 


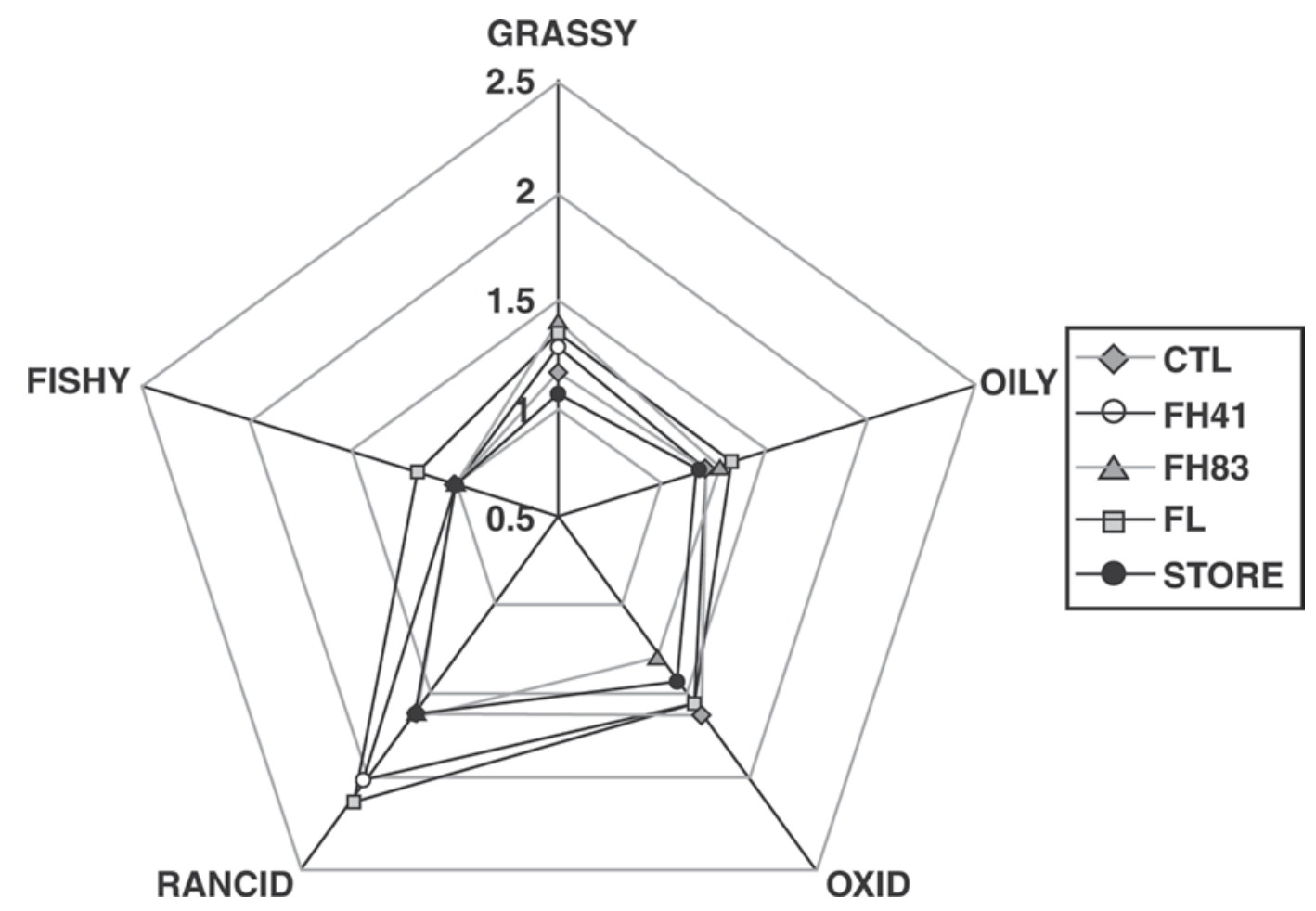

Figure 1. Descriptive analysis of milk for $3 \mathrm{~d}$ of storage, where $1=$ no flavor, $2=$ slight flavor, $3=$ moderate flavor, $4=$ strong flavor, and 5 $=$ extremely strong flavor. Treatment effect was $P=0.338,0.767,0.067,0.294$, and 0.089 for oxidized, oily, grassy, rancid, and fishy, respectively. Cows in the 4 treatments were fed either a control diet of $57 \%$ forage and $43 \%$ concentrate mix with EnerGII fat supplement at $1.65 \%$ of dietary DM (CTL), or EnerGII in the basal diet was partially replaced with 1) $0.21 \%$ partially ruminally inert calcium salts of $71 \%$ fish oil (Ca-FO71) given at $0.41 \%$ of DM (FH41); 2) $0.41 \%$ inert Ca-FO71 given at $0.83 \%$ of DM (FH83); or 3) $0.83 \%$ inert calcium salts of $43 \%$ fish oil given at $0.83 \%$ of DM (FL); STORE = control for sensory evaluation. Virtus Nutrition Inc. (Corcoran, CA) supplied all FA supplements.

other treatments could be attributed to the CLA in the EnerGII or the CLA synthesized endogenously from the FA supplied by EnerGII, as well as the enhancement of CLA production by the FO and the effects of time. This was supported by the fact that FH41, FH83, and FL all had more total CLA that the CTL, which had no FO supplementation (Table 3). Additionally, cows in the CTL treatment were known to have received EnerGII, whereas the diet for the STORE was unknown. (It should be noted that, although the CTL served as our control for the diets, the STORE served as our control for the sensory evaluation and should not be confused with the diet that was used for the control treatment.) Campbell et al. (2003) noted that milk fortified with CLA at 1 or $2 \%$ of total fat yielded a low intensity of grassy/vegetable oil off-flavor not present in the control and was deemed less acceptable by judges. Cows in this study were fed fat supplements at $1.65 \%$ of DM and showed no difference $(P<0.05)$ between treatments for grassy off-flavor. This shows that although CLA may cause a grassy off-flavor, naturally enhancing it by feeding it to cows, it creates a less intense off-flavor than direct fortification. Additionally, Khanal et al. (2005) and Lynch et al. (2005) found that milk with naturally enhanced CLA did not change its acceptably.

The slight rancid off-flavor (near an intensity of 2), although not significant $(P>0.05)$, seen in FH41 and FL after $3 \mathrm{~d}$ of storage cannot be attributed to CLA because STORE, the sensory control, was rated similarly to both CTL and FH83. If more CLA, increased by more FO, created a stronger off-flavor, then it would follow that FH83, the treatment with the highest amount of FO, would have rated the highest for rancid off-flavor. Rather, it rated the same as STORE and CTL, the treatments that received no FO. Thus, increased levels of CLA among treatments FH41, FH83, and FL did not affect $(P>0.05)$ milk flavor negatively after $3 \mathrm{~d}$ of storage. This slight off-flavor, however, may have originated from the higher content of n-6 FA observed in the milk of these treatments (Table 3). Polyunsaturated FA such as these are susceptible to rancid off-flavors. After $10 \mathrm{~d}$ of storage, FL consistently yielded off-flavor intensities of 2 (slight off-flavor) or above for rancid. Again, it was expected that perhaps FH83 would yield these results, especially fishy, because it had the most FO $(71 \%)$ per DM $(0.83 \%)$ and yielded the highest levels of EPA and 


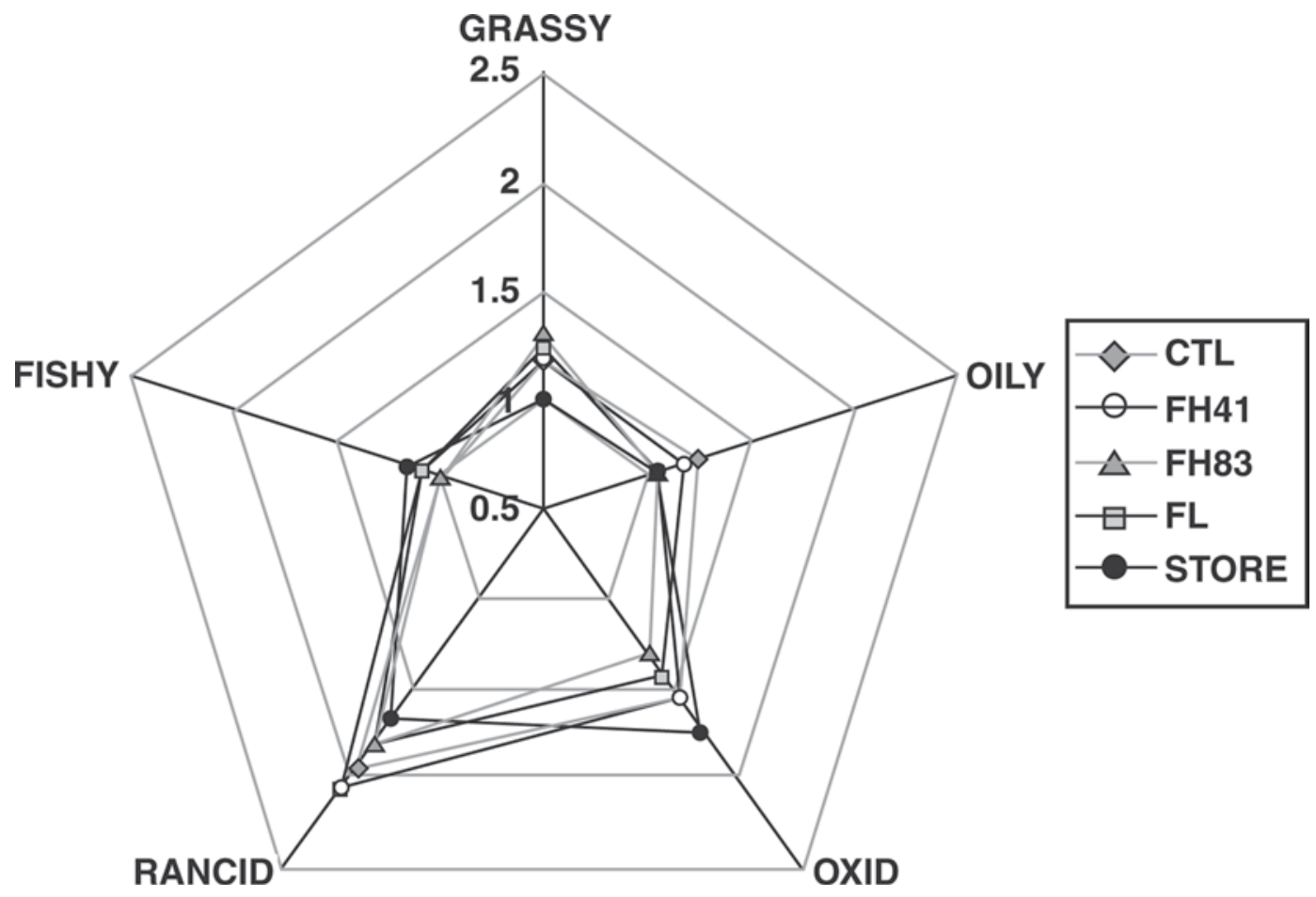

Figure 2. Descriptive analysis of milk for $10 \mathrm{~d}$ of storage, where $1=$ no flavor, $2=$ slight flavor, $3=$ moderate flavor, $4=$ strong flavor, and 5 $=$ extremely strong flavor. Treatment effect was $P=0.338,0.767,0.067,0.294$, and 0.089 for oxidized, oily, grassy, rancid, and fishy, respectively. Cows in the 4 treatments were fed either a control diet of $57 \%$ forage and $43 \%$ concentrate mix with EnerGII fat supplement at $1.65 \%$ of dietary DM (CTL), or EnerGII in the basal diet was partially replaced with 1) $0.21 \%$ partially ruminally inert calcium salts of $71 \%$ fish oil (Ca-FO71) given at $0.41 \%$ of DM (FH41); 2 ) $0.41 \%$ inert Ca-FO71 given at $0.83 \%$ of DM (FH83); or 3 ) $0.83 \%$ inert calcium salts of $43 \%$ fish oil given at $0.83 \%$ of DM (FL); STORE = control for sensory evaluation. Virtus Nutrition Inc. (Corcoran, CA) supplied all FA supplements.

DHA as well as total n-3 (Table 3), but it generally tested favorably (no significant off-flavors). Jones et al. (2005) noted that off-flavors in milk from cows fed only $45 \mathrm{~g} / \mathrm{kg}$ of FO and sunflower oil were detected the majority of the time when compared with milk from cows that were fed either FO or sunflower oil alone. This shows that even small amounts of polyunsaturated fats in the milk are susceptible to off-flavors.

The oily off-flavor came close to having a significant difference between storage days $(P=0.05)$, with $\mathrm{d} 3$ having an average rating of $1.24( \pm 0.6)$ and $\mathrm{d} 10$ having a rating of $1.13( \pm 0.6$; Table 4$)$. Interestingly, only the CTL was found to have gained an oily off-flavor (1.25) when compared with the other treatments (1.06 for FH83, FL, and STORE; and 1.19 for FH41) after $10 \mathrm{~d}$ of storage. The oily off-flavor detected in the CTL was probably a consequence of the higher percentage of fat present in this sample $(3.41 \%$ vs. $3.28,2.63$, and $3.25 \%$ for FH41, FH83, and FL, respectively, although not statistically significant; unpublished data). Diets rich in FO resulted in milk fat depression; therefore, the CTL samples, with no FO, resulted in higher amounts of fat, which were detected as slightly oily off-flavors. When cows were fed a diet with extruded full-fat soybeans or soybean oil with 2.7\% FO, Allred et al. (2006) found no difference among treatment milks for off-flavors, including oily. Although these diets contained more dietary fat $(4.61,6.28,6.77$, and $6.62 \mathrm{~g} / 100 \mathrm{~g})$ than the diets in this study (1.65\% of DM), and thus would likely have resulted in more intense oily off-flavors, the higher level of FO $(2.7 \%)$ may have depressed the higher fat.

Interestingly, after $3 \mathrm{~d}$ of storage, only FL, the treatment with the least amount of FO but the highest amount of EPA, rated slightly higher than the other treatments for fishy off-flavor (Table 3). The mean intensity for fishy off-flavors for all treatments combined during this period was $1.04( \pm 0.10)$. After $10 \mathrm{~d}$ of storage, the treatments rated similarly, all near 1 with a slightly higher mean of $1.05( \pm 0.10)$. Allred et al. (2006) found that even when fed at $2.7 \%$ of DM, FO did not alter sensory evaluations when compared with the control for fishy off-flavor. In fact, many researchers focus on the oxidized off-flavor in milk with naturally enhanced FO because of its high polyunsaturated FA content, rather than focusing on the fishy off-flavor. This may be attributed to the fact that protecting FO, such as with calcium salts or protein matrices, reduces the fishy off-flavor in milk, as demonstrated by Lacasse 
Table 4. Average intensities of off-flavors between treatments detected in milk from cows fed calcium salts of fish oil (FO) and EnerGII ${ }^{1}$ at varying levels during certain periods of sampling and storage

\begin{tabular}{lccccc}
\hline & \multicolumn{5}{c}{ Off-flavor intensity ${ }^{3,4}$} \\
\cline { 2 - 5 } Time period ${ }^{2}$ & Oxidized & Fishy & Grassy & Rancid & Oily \\
\hline $3 \mathrm{~d}$ & $1.49(0.06)$ & $1.04(0.01)$ & $1.24(0.14)$ & $1.79(0.23)$ & $1.24(0.60)$ \\
$10 \mathrm{~d}$ & $1.53(0.06)$ & $1.05(0.01)$ & $1.19(0.14)$ & $1.86(0.23)$ & $1.13(0.60)$ \\
Average & $1.51(0.06)$ & $1.05(0.01)$ & $1.22(0.14)$ & $1.83(0.23)$ & $1.34(0.60)$ \\
\hline${ }^{1}$ Virtus Nutrition Inc. (Corcoran, CA) supplied all FA supplements, including EnerGII. \\
${ }^{2}$ Days milk was stored before being evaluated. \\
${ }^{3}$ Values represent means of intensities of treatments combined for each off-flavor. Evaluated on a 5-point scale, \\
where 1 = no flavor, 2 = slight flavor, 3 = moderate flavor, 4 = strong flavor, and 5 = extremely strong fla- \\
vor. \\
${ }^{4}$ Values in parentheses equal standard error of the least squares means (SEM).
\end{tabular}

et al. (2002), and also maintains DMI of the cows and, consequently, BW and milk production.

After $3 \mathrm{~d}$ of storage, treatments FH41, FL, and CTL all had intensities for oxidized off-flavor that were above an intensity of 1.5 . Nothing in the production variables or FA composition clearly indicated why these 3 diet treatments, compared with FH83 and STORE, had intensities close to the barely perceptible intensity for oxidized. After $10 \mathrm{~d}$, treatments CTL, FL, and STORE rated above 1.5 for oxidized off-flavor, again with no indicator to explain this. The STORE treatment seemed to have a more intense oxidative flavor (1.75) when compared with the other treatments (1.56 for CTL and FL; 1.44 for FH41; and 1.31 for FH83). This may have been due to packaging because it was in a clear plastic jug. Similarly, Allred et al. (2006) found a store-purchased control to be of lower overall quality when compared with the other treatments. They also conjectured that this result was caused by packaging. Additionally, Lacasse et al. (2002) noted that their control (milk from cows fed no FO) yielded a slight oxidized off-flavor. A study by Ramaswamy et al. (2001) showed that milk from cows fed a diet with only FO supplemented yielded lower scores (less off-flavor) for oxidized flavor detected than for those from cows fed only extruded soybeans. They also noted a higher score for cows fed both FO and extruded soybeans after $3 \mathrm{~d}$ of storage when compared with FO alone, but a lower score when compared with only extruded soybeans.

Although all the off-flavors had ratings, the majority of them were close to 1 , which indicated no off-flavor. The highest ratings detected were only near 2.5 (where $1=$ no off-flavor, $2=$ slight off-flavor, and $3=$ moderate off-flavor). The detection of some off-flavors in all the milk samples on either day of storage, including STORE, may be explained by the judges and their use of the scale. Some may have felt uncomfortable using 0 and instead may have rated the sample at 1 . Despite this, however, the fact that STORE rated similarly to the treatments that contained FO after both storage days was evidence that the increased levels of CLA, EPA, and DHA had little impact on milk off-flavors.

Although a Consumer Acceptability Sensory Evaluation was not conducted, it could be possible that milk from cows fed these diets would be found generally acceptable and fit for sale. This seems to be supported by the fact that the STORE milk in our experiment often seemed to possess an off-flavor. This shows that despite the presence of low-intensity off-flavors, the quality and taste of milk would be comparable with, if not better than, milk currently sold in the store, and any off-flavors detected in the milk from cows fed the diets in this experiment could not necessarily be attributed to FO, EnerGII, or their combination.

\section{CONCLUSIONS}

There were no significant differences between milk samples from each of the treatments, storage days, or their interaction. Only low-intensity off-flavors (no higher than 2.5 , where $1=$ no off-flavor, $2=$ slight, and $3=$ moderate) were detected in any of the milk samples from any day of storage. Rancid, not fishy, off-flavors were most often detected. Treatment FL, the treatment with the lowest level of FO in the diet, contained most of the off-flavors detected. The STORE control often had detectable off-flavors; therefore, any detectable offflavors in the experimental milk could not necessarily be attributed to FO, EnerGII, or their combination.

Milk from cows fed varying levels of FO and EnerGII generally yielded little to no off-flavor. Treatment FL seemed to be the most viable diet for actual use in production when health of the cow, DMI, milk yield, production variables, and sensory evaluations were considered. Enhanced milk such as that created in this experiment would prove to be an important factor and a benefit to a balanced, healthy diet. 


\section{ACKNOWLEDGMENTS}

Gratitude goes to Robert Ward for his expertise on the FA analysis, to Maureen Stuart and Chris Dschaak for their help, and to all who participated in this project in any way. Many thanks go to Virtus Nutrition (Corcoran, CA) for funding this project and supplying the supplements. Special thanks go to Kevin Murphy for his expertise and ease of cooperation. Recognition goes to T. R. Dhiman for his work on the protocol for this project. This manuscript was approved by the Utah Agricultural Station as paper number 8007.

\section{REFERENCES}

Allred, S. L., T. R. Dhiman, C. P. Brennand, R. C. Khanal, D. J. McMahon, and N. D. Luchini. 2006. Milk and cheese from cows fed calcium salts of palm and fish oil alone or in combination with soybean products. J. Dairy Sci. 89:234-248.

Baer, R. J., J. Ryali, D. J. Schingoethe, K. M. Kasperson, D. C. Donovan, A. R. Hippen, and S. T. Franklin. 2001. Composition and properties of milk and butter from cows fed fish oil. J. Dairy Sci. 84:345-353.

Campbell, W., M. A. Drake, and D. K. Larick. 2003. The impact of fortification with conjugated linoleic acid (CLA) on the quality of fluid milk. J. Dairy Sci. 86:43-51.

Chouinard, P. Y., L. Corneau, D. M. Barbano, L. E. Metzger, and D. E. Bauman. 1999. Conjugated linoleic acid alters milk fatty acid composition and inhibits milk fat secretion in dairy cows. J. Nutr. 129:1579-1584.

Chouinard, P. Y., L. Corneau, W. R. Butler, Y. Chilliard, J. K. Drackley, and D. E. Bauman. 2001. Effect of dietary lipid source on conjugated linoleic acid concentrations in milk fat. J. Dairy Sci. 84:680-690.

Croissant, A. E., S. P. Washburn, L. L. Dean, and M. A. Drake. 2007. Chemical properties and consumer perception of fluid milk from conventional and pasture-based production systems. J. Dairy Sci. 90:4942-4953.

Dhiman, T. R., S. Nam, and A. L. Ure. 2005. Factors affecting conjugated linoleic acid content in milk and meat. Crit. Rev. Food Sci. Nutr. 45:463-482.

Donovan, D. C., D. J. Schingoethe, R. J. Baer, J. Ryali, A. R. Hippen, and S. T. Franklin. 2000. Influence of dietary fish oil on conjugated linoleic acid and other fatty acids in milk fat from lactating dairy cows. J. Dairy Sci. 83:2620-2628.

Hongsoongnern, P., and E. Chambers IV. 2008. A lexicon for green odor or flavor and characteristics of chemicals associated with green. J. Sens. Stud. 23:205-221.
Hughes, C. L., and T. R. Dhiman. 2002. Dietary compounds in relation to dietary diversity and human health. J. Med. Food 5:51-68.

Hurley, W. L., G. J. Warner, and R. R. Grummer. 1987. Changes in triglyceride fatty acid composition of mammary secretions during involution. J. Dairy Sci. 70:2406-2410.

Jones, E. L., K. J. Shingfield, C. Kohen, A. K. Jones, B. Lupoli, A. S. Grandison, D. E. Beever, C. M. Williams, P. C. Calder, and P. Yaqoob. 2005. Chemical, physical, and sensory properties of dairy products enriched with conjugated linoleic acid. J. Dairy Sci. 88:2923-2937.

Khanal, R. C., T. R. Dhiman, A. L. Ure, C. P. Brennand, R. L. Boman and D. J. McMahon. 2005. Consumer acceptability of conjugated linoleic acid-enriched milk and Cheddar cheese from cows grazing on pasture. J. Dairy Sci. 88:1837-1847.

Kolanowski, W., and J. Weißbrodt. 2007. Sensory quality of dairy products fortified with fish oil. Int. Dairy J. 17:1248-1253.

Lacasse, P., J. J. Kennelly, L. Delbecchi, and C. E. Ahnadi. 2002. Addition of protected and unprotected fish oil to diets for dairy cows. I. Effects on yield, composition and taste of milk. J. Dairy Res. 69:511-520.

Lynch, J. M., A. L. Lock, D. A. Dwyer, R. Noorbakhsh, D. M. Barbano, and D. E. Bauman. 2005. Flavor and stability of pasteurized milk with elevated levels of conjugated linoleic acid and vaccenic acid. J. Dairy Sci. 88:489-498.

Meilgaard, M. C., G. V. Civille, and B. T. Carr. 2007. Sensory Evaluation Techniques. 4th ed. CRC Press, Boca Raton, FL.

NRC. 2001. Nutrient Requirements of Dairy Cattle. 7th ed. Natl. Acad. Press, Washington, DC.

Ramaswamy, N., R. J. Baer, D. J. Schingoethe, A. R. Hippen, K. M. Kasperson, and L. A. Whitlock. 2001. Composition and flavor of milk and butter from cows fed fish oil, extruded soybeans, or their combination. J. Dairy Sci. 84:2144-2151.

Ruxton, C. 2004. Health benefits of omega-3 fatty acids. Nurs. Stand. 18:38-42.

SAS Institute. 1999-2000. SAS/STAT User's Guide. Release 8.1. SAS Inst. Inc., Cary, NC.

Shipe, W. F., R. Bassette, D. D. Deane, W. L. Dunkley, W. J. Harper, D. H. Kleyn, M. E. Morgan, J. H. Nelson, and R. A. Scanlan. 1977. Off flavors of milk: Nomenclature, standards, and bibliography. J. Dairy Sci. 61:855-869.

Simopoulos, A. P. 1991. Omega-3 fatty acids in health and disease and in growth and development. Am. J. Clin. Nutr. 54:438-447.

Singh, T. K., M. A. Drake, and K. R. Cadwallader. 2003. Flavor of Cheddar cheese: A chemical and sensory perspective. Compr. Rev. Food Sci. Food Saf. 2:139-162.

Whitlock, L. A., D. J. Schingoethe, A. A. Abu-Ghazaleh, A. R. Hippen, and K. F. Kalscheur. 2006. Milk production and composition from cows fed small amounts of fish oil with extruded soybeans. J. Dairy Sci. 89:3971-3980. 